\title{
Nonlinear Time-Course Uptake of Carbon and Ammonium by Marine Phytoplankton*
}

\author{
Joel C. Goldman ${ }^{1}$, Craig D. Taylor ${ }^{1}$ and Patricia M. Glibert ${ }^{2}$ \\ 1 Woods Hole Oceanographic Institution, Woods Hole, Massachusetts 02543, USA \\ 2 Museum of Comparative Zoology, Harvard University, Cambridge, Massachusetts 02138, USA
}

\begin{abstract}
In a series of laboratory and field experiments with natural and cultured marine phytoplankton the shapes of the time-dependent uptake curves of ${ }^{15} \mathrm{NH}_{4}^{+}$and $\mathrm{H}^{14} \mathrm{CO}_{3}^{-}$were determined. Non-linearity in ${ }^{14} \mathrm{C}$ uptake in laboratory cultures did not seem to be a function of steady state growth rate. However, temperature did appear to affect the degree to which ${ }^{14} \mathrm{C}$ is incorporated in a linear manner for Thalassiosira weissflogii between $8^{\circ}$ and $25^{\circ} \mathrm{C}$ and Dunaliella tertiolecta below $10^{\circ} \mathrm{C}$, but not for the other species investigated. Deviations from linearity for both $\mathrm{H}^{14} \mathrm{CO}_{3}^{-}$and ${ }^{15} \mathrm{NH}_{4}^{+}$ uptake in both laboratory and field experiments could be correlated with $\mathrm{NH}_{4}^{+}$depletion, especially when $\mathrm{NH}_{4}^{+}$levels at the start of the incubations did not exceed a few tenths $\mu \mathrm{g} \mathrm{at} \mathrm{l}^{-1}$. The distribution of $\mathrm{C}$ and $\mathrm{N}$ among subcellular components was also investigated during the field experiments. The results demonstrated that by analyzing compositional changes among subcellular components a much improved estimate of the metabolic state of confined phytoplankton may be obtained. Our results demonstrate that there are severe incompatabilities between choosing an incubation period based solely on analytical requirements from one based on the best representation of the time scale of physiological responses by phytoplankton. Time-course experiments allow us to understand better the short-term responses by phytoplankton, environmental influences on uptake, such as light and temperature, and to identify analytical problems or bottle effects, such as nutrient depletion.
\end{abstract}

\section{INTRODUCTION}

Of major importance to marine phytoplankton ecologists is the ability to make accurate rate measurements of phytoplankton growth, primary production, and nutrient uptake in the natural environment. Such measurements are crucial to our understanding of the basic physiology and ecology of phytoplankton. Yet presently there is considerable disagreement in the literature as to the magnitude of these rates and the reliability of the measurement techniques commonly employed (Eppley, 1980a).

The standard techniques that have evolved for measuring the above rates generally involve confinement of a natural water sample in small bottles for a long (hours to tens of hours) duration with an added isotopic tracer (e. g. ${ }^{14} \mathrm{CO}_{2},{ }^{15} \mathrm{NH}_{4}^{+},{ }^{15} \mathrm{NO}_{3}$ ) followed by a single end-point measurement of the quantity of tracer incorporated into particulate material

\footnotetext{
- Contribution No. 4868 from the Woods Hole Oceanographic Institution
}

(Steemann Nielsen, 1952; Dugdale and Goering, 1967). A critical assumption upon which the utility of these techniques is based is that the measured biological activity in the assay bottle is identical to that in the undisturbed natural environment from which the sample was derived. Furthermore, it is assumed that the rate of incorporation of label is linear over the course of an incubation. To date, virtually all of our knowledge of primary production and nutrient turnover in the oceans is based on data collected with these techniques.

In recent years numerous problems with bottle incubation techniques have been addressed, including, for example, changes in plankton species composition during confinement (Venrick et al., 1977), bottle size and incubation duration (Gieskes et al., 1979), light response artifacts (Harris and Piccinin, 1977, Marra, 1978), other types of contamination from bottles, such as trace metal toxicity (Carpenter and Lively, 1980), and non-linearity in short-term nutrient uptake responses (Conway et al., 1976; Glibert and Goldman, 1981). Hence, we are faced with a dilemma as to how 
bottle assays can be used to represent accurately the true time-dependent photosynthetic and nutrient uptake responses of undisturbed natural phytoplankton on time scales (possibly seconds to minutes) that may be important to individual cells (McCarthy and Goldman, 1979, Harris, 1980). This question has relevancy to the current debates about the importance of short-term responses and the magnitude of phytoplankton growth and production rates (Sheldon and Sutcliffe, 1978; Gieskes et al., 1979; Goldman et al., 1979; McCarthy and Goldman, 1979; Eppley, 1980a, b; Jackson, 1980).

Thus, in any consideration of rate measurements of uptake or growth, it has become imperative that the shape of the time-dependent uptake curve be established in order to understand better both physiological responses of phytoplankton to nutrients and the magnitude of some of the above problems. To date, however, these types of data are largely unavailable. Rather, the literature is replete with rate measurements from nutrient and carbon uptake experiments of varying and often arbitrary durations involving single end-point determinations. Clearly, single end-point measurements provide no insight into the actual physiological response of cell populations over time (Morris et al., 1974; Mague et al., 1980). For example, as seen in Fig. 1, drastically different uptake processes will remain undetected and lead to the same computed rates when single endpoint measurements are made. In theoretical Cases A and B (Fig. 1) rates of tracer incorporation are initially rapid, but losses in biological activity or tracer depletion many result in significant and time dependent decreases in these rates. In Case A release of tracer from the particulate material

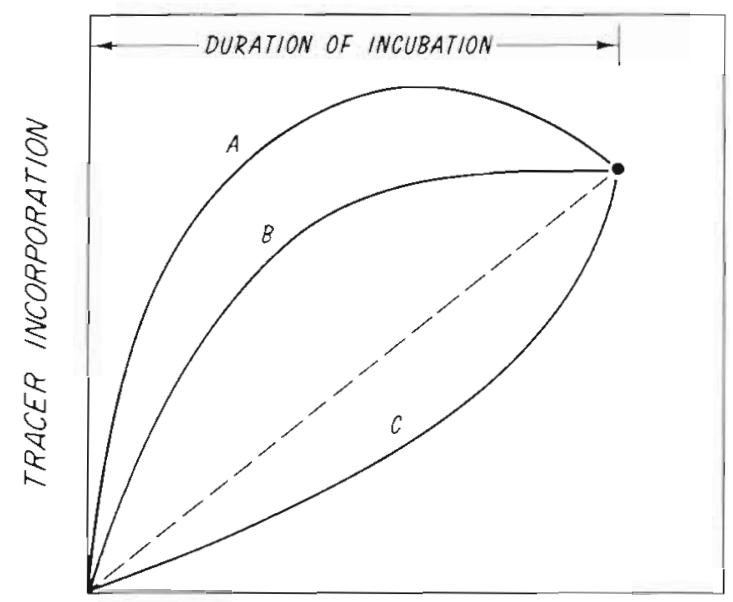

INCUBATION PERIOD

Fig. 1 Theoretical non-linear uptake responses $(A-C)$ that would lead to the same net accumulation of tracer as a linear response (dashed line) when computed from single end-point measurements back into the medium is enhanced when excretory, lytic, and/or respiratory phenomend increase over initial rates, whereas, in Case B continued incubation leads to total cessation of tracer incorporation. Finally, in theoretical Case $\mathrm{C}$ there is an initial lag in tracer incorporation followed by an increased rate toward the end of the incubation period as enhanced cell growth or nutrient uptake capability is induced.

Moreover, virtually no data exist on simultaneous carbon and nutrient uptake measurements over timecourses and the influence of environmental parameters such as temperature and light on the dynamics of these processes. Such data could provide important information about the degree and mechanisms of coupling between photosynthesis and nutrient uptake and shed new insight as to the utility of rate measurements from bottle assays.

In this paper we present a series of laboratory and field studies involving time-course measurements of photosynthetic ${ }^{14} \mathrm{C}$ and ${ }^{15} \mathrm{NH}_{4}^{+}$uptake by marine phytoplankton. Our main objective is to demonstrate that non-linearity in uptake response is a common occurrence, detectable only in time-course studies, and that single end-point measurements of rate processes often can distort the interpretation of rate measurement data.

\section{MATERLALS AND METHODS}

\section{Laboratory Studies}

Four marine phytoplankton species - Dunaliella tertiolecta (Dun), Phaeodactylum tricornutum (TFX-1), Chaetoceros simplex (BBsm), and Thalassiosira weissflogii (Actin) - were obtained from the culture collection at Woods Hole Oceanographic Institution and grown to steady state in $\mathrm{NH}_{4}^{+}$-limited continuous cultures at varying dilution rates ( $=$ specific growth rates $\mu$ and temperatures. The continuous culture apparatus, lighting, temperature-control system, and protocols for cultivation were exactly as described previously (Goldman and McCarthy, 1978; Goldman and Peavey, 1979).

Once steady state was achieved for a particular combination of temperature and dilution rate, samples were withdrawn and divided into 2 portions. One portion was used for analyses of residual $\mathrm{NH}_{4}^{+}$and total dissolved inorganic carbon (DIC), and the other for the ${ }^{14} \mathrm{C}$ and/or ${ }^{15} \mathrm{~N}$ time-course incubations. Analyses of cell number, particulate carbon and particulate nitrogen also were made, but these data are not reported here. A bank of ten-150 ml water-jacketed glass (Pyrex) incubation vessels was maintained at the same light intensity $\left(0.06 \mathrm{cal} \mathrm{cm}^{-2} \mathrm{~min}^{-1}\right)$ and temperature as for the continuous cultures. Mixing was accomplished 


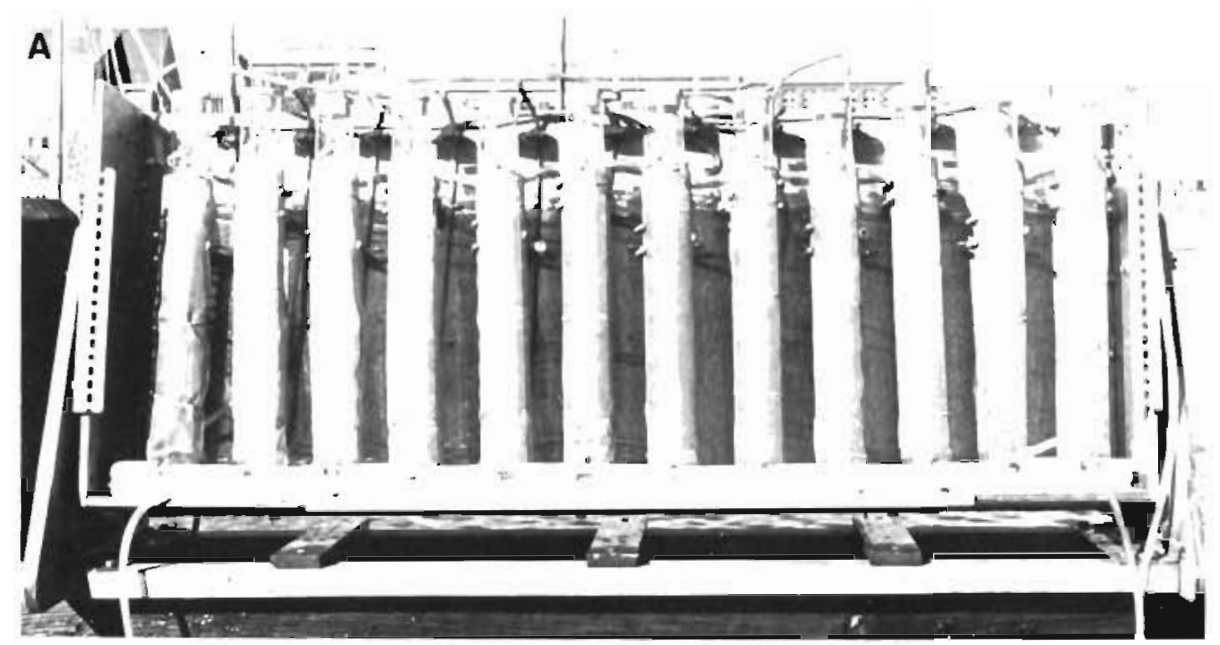

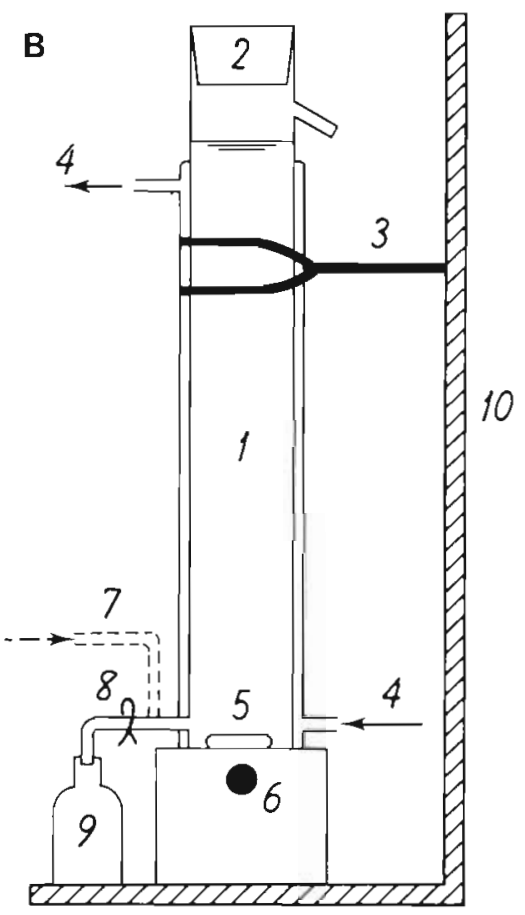

by magnetic bar stirring. The time course experiments were performed by first adding the desired amount of $\mathrm{H}^{14} \mathrm{CO}_{3}^{-}\left(0.5 \mu \mathrm{Ci} \mu \mathrm{Mole} \mathrm{DIC}^{-1}\right)$ or ${ }^{15} \mathrm{NH}_{4}^{+}$(99\% enriched preparation), followed by the culture sample. Subsamples were withdrawn by pipet at designated times during the incubations, ranging from $5 \mathrm{~min}$ to 3 to $4 \mathrm{~h}$ in most cases, and, for some experiments, up to $24 \mathrm{~h}$. In all the ${ }^{15} \mathrm{~N}$ uptake experiments $16 \mu \mathrm{g}$ at $\mathrm{l}^{-1}$ of ${ }^{15} \mathrm{NH}_{4}^{+}$ was added which was sufficient to saturate the uptake system. In some ${ }^{14} \mathrm{C}$ experiments replicate assays were performed, one with a supplement of $16 \mu \mathrm{g}$ at $\mathrm{l}^{-1}$ of $\mathrm{NH}_{4}^{+}$(unenriched in ${ }^{15} \mathrm{~N}$ ) and another without supplemental $\mathrm{NH}_{4}^{+}$addition. The disappearance of residual $\mathrm{NH}_{4}^{+}$over time was followed in a few $24 \mathrm{~h}{ }^{15} \mathrm{~N}$ uptake experiments.
Fig. 2. Time-course incubation system: (A) Complete system consisting of twelve 1-l incubation units mounted on portable stand. (B) Schematic diagram of one unit. 1: 1-1 vessel with water jacket; 2: rubber stopper; 3: clamp; 4: inflow and outflow ports for temperaturecontrolled water; 5: Tefion-coated stirring bar for mixing of $\mathrm{H}^{14} \mathrm{CO}_{3}^{-}$-containing cultures; 6 : magnetic mixer; 7 : air line from aquarium pump for mixing during ${ }^{15} \mathrm{~N}$-uptake studies; 8 : culture sampling port with pinch clamp; 9: sampling bottle; 10: wood support frame

\section{Field Studies}

Two $30 \mathrm{~h}$ time-course studies were carried out on water samples obtained from a station in Vineyard Sound, Massachusetts, midway between Martha's Vineyard and Woods Hole. Samples were collected from $1 \mathrm{~m}$ depth with 6-1 Niskin sampling bottles at sunrise on July 24, 1980 (Experiment 1) and July 30, 1980 (Experiment 2) aboard R. V. 'Asterias', filtered through $35 \mu \mathrm{m}$ Nitex mesh, and returned to shore where the incubation studies were performed outdoors.

The incubation system consisted of two banks of 1-1 water-jacketed glass (Pyrex) chambers. One bank consisting of 12 units was used for the ${ }^{15} \mathrm{~N}$ studies (Fig. 2A) 
and the other bank of 6 units was split between ${ }^{15} \mathrm{~N}(2$ units) and ${ }^{14} \mathrm{C}$ (4 units) studies. The chambers were held at ambient temperature by circulating surface seawater through the water jackets of each chamber from a flowing seawater line, and neutral density screens were used to simulate the $60 \%$ light level. Mixing in the ${ }^{14} \mathrm{C}$ units was performed via magnetic bar stirring and in the ${ }^{15} \mathrm{~N}$ units by gentle bubbling of air provided by a small aquarium pump (Fig. 2B). A valved port at the base of each chamber was used to remove subsamples by gravity flow.

The incubations were initiated at 0800 on the first day of each study and progressed until 1400 the following day. The ${ }^{15} \mathrm{~N}$ uptake studies were initiated by the addition of $0.06 \mu \mathrm{g}$ at $\mathrm{l}^{-1}$ or $12 \mu \mathrm{g}$ at $\mathrm{l}^{-1}$ of ${ }^{15} \mathrm{NH}_{4}^{+}$into each of the chambers containing $950 \mathrm{ml}$ of sample. These additions will be referred to as 'trace' and 'saturating' respectively, although, as Glibert and Goldman (1981) point out, when ambient $\mathrm{NH}_{4}^{+}$concentrations border on our limit of detection it is impossible to enrich at true 'trace' levels without perturbing the system. At timed intervals $300-350 \mathrm{ml}$ of ${ }^{15} \mathrm{~N}$ enriched samples were selected in non-sequential order, drained, and immediately filtered. Selected samples from the ${ }^{15} \mathrm{~N}$ assays were treated with $30-35$ $\mathrm{ml}$ of $100 \%$ trichloroacetic acid (TCA) prior to filtration. On a less frequent schedule samples were withdrawn for analyses of residual $\mathrm{NH}_{4}^{+}$, particulate carbon, particulate nitrogen, and chlorophyll $a$.

${ }^{15} \mathrm{~N}$ uptake rates were not corrected for dilution of the ${ }^{15} \mathrm{~N}$ isotopic enrichment resulting from regeneration of ${ }^{14} \mathrm{~N}$ during the incubation. Without this correction $\mathrm{NH}_{4}^{+}$uptake will be underestimated, particularly for incubations of long duration (Glibert et al., unpubl.). Because the appropriate analyses of ${ }^{15} \mathrm{~N}$ enrichment of the aqueous fraction throughout the time course were not done, we have no data to guide us in estimating the degree to which rates of $\mathrm{NH}_{4}^{+}$uptake were underestimated. The isotope dilution correction would not be important for laboratory grown cultures unless there was severe bacterial contamination.

${ }^{14} \mathrm{C}$-uptake measurements were begun by introducing $\mathrm{H}^{14} \mathrm{CO}_{3}^{-}$to yield a specific activity of $80-100 \mu \mathrm{Ci}$ mMole DIC ${ }^{-1}$, and where indicated, trace $\left(0.06 \mu \mathrm{g}\right.$ at $\left.\mathrm{l}^{-1}\right)$ or saturating $\left(12 \mu \mathrm{g}\right.$ at $\left.\mathrm{l}^{-1}\right)$ amounts of $\mathrm{NH}_{4}^{+}$were also added. A dark control experiment was conducted in a blackened chamber (unenriched with $\mathrm{NH}_{4}^{+}$) in an identical fashion as in the light experiments. Fifty ml samples were withdrawn from each unit on a similar timetable as for the ${ }^{15} \mathrm{~N}$ samples. Activity corrections were made for changes occurring over the $30 \mathrm{~h}$ incubations.

Solar irradiance (visible plus IR region) was measured with an International Light Radiometer (No. 700) during the course of each study.

\section{Analytical Methods}

Chemical analyses for particulate carbon and particulate nitrogen were performed with a Perkin Elmer 240 elemental analyzer on samples retained on precombusted glass fiber filters (Whatman GF/F). $\mathrm{NH}_{4}^{+}$ was measured on filtered samples immediately after collection (McCarthy and Kamykowski, 1972; Strickland and Parsons, 1972). DIC was measured on a Dohrmann PR-1 carbon analyzer (Goldman, 1979).

${ }^{15} \mathrm{~N}$ incubations were terminated at the designated times by the filtration of sample onto glass fiber filters (combusted Whatman $\mathrm{GF} / \mathrm{C}$ or $\mathrm{GF} / \mathrm{F}$ ). Filters were immediately washed with $50 \mathrm{ml}$ of filtered seawater to remove residual ${ }^{15} \mathrm{~N}$, dryed, and assayed for ${ }^{15} \mathrm{~N}$ incorporation by mass spectrographic analysis (McCarthy et al., 1977). All ${ }^{15} \mathrm{~N}$ uptake data are reported as ${ }^{15} \mathrm{~N}$ atom $\%$ excess, defined as the percent enrichment above normal atmospheric background ( $0.365 \%)$.

${ }^{14} \mathrm{C}$ incubations were terminated in the laboratory studies by pipeting $1 \mathrm{ml}$ of sample at the designated times into scintillation vials containing $2 \mathrm{ml}$ of methanol acidified with $5 \%$ glacial acetic acid. The vial contents were evaporated to dryness under an infra-red lamp, resuspended in $1 \mathrm{ml}$ distilled water, followed by an addition of $10 \mathrm{ml}$ scintillation fluid (Handifluor) for counting. The measured radioactivity represents the sum of labelled particulate and nonvolatile dissolved organic carbon (Schindler and Holmgren, 1971; Li and Goldman, 1981). For field studies the samples were initially collected into $60 \mathrm{ml}$ bottles containing $0.1 \mathrm{ml} 18 \mathrm{~N} \mathrm{H}_{2} \mathrm{SO}_{4}$ to lower the sample $\mathrm{pH}$ to $\sim 1.7$. Samples were then filtered through 0.45 um membrane filters (Millipore, HA) and rinsed once with $3 \mathrm{ml}$ of $5 \%$ TCA. Filters were placed in scintillation vials containing $5 \mathrm{ml}$ of scintillation fluid (Aquasol). The pooled filtrates were sparged with air $\left(200 \mathrm{ml} \mathrm{min}^{-1}\right)$ for $10 \mathrm{~min}$ to remove ${ }^{14} \mathrm{CO}_{2}$ and then $5 \mathrm{ml}$ were added to scintillation vials containing $9 \mathrm{ml}$ of Aquasol. With this procedure it was possible to collect and fix samples rapidly, as was required in our time series experiments involving multiple incubations. The samples were then processed at a more convenient time for determination of acid insoluble polymers, i. e. sum of proteins, carbohydrates, lipids, and nucleic acids (filtered material), and the sum of intracellular and extracellular organic carbon pools (filtrate). Although the technique gives results that are quantitatively comparable to the more conventional acid fixation techniques involving treatment with $5 \%$ TCA (Roberts et al., 1963), it suffers from the major disadvantage of not being able to separate intracellular from extracellular carbon pools, thereby preventing a description of the rate exudate production. 


\section{RESULTS}

\section{Laboratory Studies}

The incorporation of carbon over 24 h by Thalassiosira weissflogii for samples incubated with and without an enrichment of $16.0 \mu \mathrm{g}$ at $1^{-1} \mathrm{NH}_{4}^{+}$is shown in Fig. 3. The culture had been grown to a steady state $\mu$ of 1.6 $\mathrm{d}^{-1}$ at $25^{\circ} \mathrm{C}$ and residual $\mathrm{NH}_{4}^{+}$was $0.75 \mu \mathrm{g}$ at $\mathrm{l}^{-1}$. Uptake of ${ }^{14} \mathrm{C}$ in both samples was comparable only for the first 90-120 min of the incubation. In the absence of supplemental $\mathrm{NH}_{4}^{+}$linear ${ }^{14} \mathrm{C}$ incorporation occurred for the first $3 \mathrm{~h}$. Thereafter, ${ }^{14} \mathrm{C}$ fixation rates diminished continuously, such that by $24 \mathrm{~h}$ observed rates were 9 fold reduced from values obtained initially. The $\mathrm{NH}_{4}^{+}$enriched culture, on the other hand, was characterized by linear incorporation of tracer for up to $\sim 7 \mathrm{~h}$, followed by significant decreases in the uptake rate for the next $4-5 \mathrm{~h}$. Between 12 and $24 \mathrm{~h}$ a portion of the incorporated ${ }^{14} \mathrm{C}$ was lost from the system. Because ${ }^{14} \mathrm{C}$ incorporation was expressed as the sum of particulate and dissolved organic carbon in these experiments, the observed losses of label most likely resulted from remineralization of fixed carbon, perhaps by bacteria present in the cultures.

Experiments similar to the above, but which included the simultaneous measurement of ${ }^{15} \mathrm{NH}_{4}^{+}$and $\mathrm{H}^{14} \mathrm{CO}_{3}^{-}$uptake, were performed with cultures of Chaetoceros simplex and Phaeodactylum tricornutum pre-grown to steady state $\mu$ values of 0.20 and $0.63 \mathrm{~d}^{-1}$ at $16{ }^{\circ} \mathrm{C} .{ }^{15} \mathrm{~N}$ uptake experiments were continued for 24 $\mathrm{h}$, whereas the ${ }^{14} \mathrm{C}$ incubations were terminated after 3 h. For both species ${ }^{14} \mathrm{C}$ uptake was linear over the $3 \mathrm{~h}$

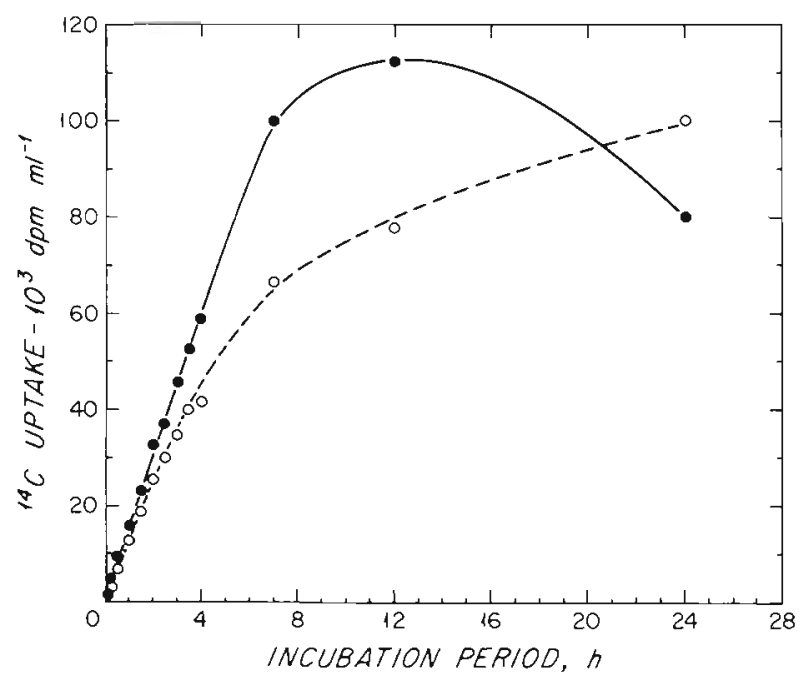

Fig. 3. Thalassiosira weissflogii. 24-h time-course of $\mathrm{H}^{14} \mathrm{CO}_{3}^{-}$ uptake. Culture was first grown to steady state at $25^{\circ} \mathrm{C}$ and $\mu$ of $1.6 \mathrm{~d}^{-1}$ in $\mathrm{NH}_{4}^{+}$-limited continuous culture; enriched with $16 \mu \mathrm{g}$ at $\mathrm{I}^{-1}$ of $\mathrm{NH}_{4}^{+}$at start of incubation; $O$ unenriched incubation period (Fig. 4A, B) irrespective of whether supplemental $\mathrm{NH}_{4}^{+}$was added or not. In contrast, ${ }^{15} \mathrm{NH}_{4}^{+}$uptake was distinctly non-linear for C. simplex during the first $2 \mathrm{~h}$ of incubation and then ceased for the remainder of the experiment (Fig. 4A, C). A similar but less dramatic deviation from linearity was observed for ${ }^{15} \mathrm{NH}_{4}^{+}$uptake by $P$. tricornutum (Fig. 4B. D). Residual $\mathrm{NH}_{4}^{+}$diminished during the course of the incubations from over $17 \mu \mathrm{g}$ at $\mathrm{l}^{-1}\left(16 \mu \mathrm{g}\right.$ at $\mathrm{l}^{-1}$ enrichment plus the ambient concentration) at the start to $\leq 2.2 \mu \mathrm{g}$ at $\mathrm{l}^{-1}$ after $4 \mathrm{~h}$ (Fig. $4 \mathrm{C}, \mathrm{D}$ ).

Experiments were conducted to determine whether the onset of non-linear (slowed) uptake of ${ }^{14} \mathrm{C}$ by the same laboratory species was a function of either steady state $\mu$ or temperature of incubation. In Fig. 5 the time course of ${ }^{14} \mathrm{C}$ uptake by Thalassiosira weisfloggii and Dunaliella tertiolecta over $4 \mathrm{~h}$ is shown. The deviation from linear carbon uptake in studies involving $T$. weissflogii did not appear to be a function of steady state $\mu$. Departure from linear uptake kinetics occurred at very similar times ( 2 to $2.5 \mathrm{~h}$ ) even though the initial specific growth rate of the incubating cultures ranged from 0.2 to $2.2 \mathrm{~d}^{-1}$ at $25^{\circ} \mathrm{C}$ (Fig. 5B). By comparison, virtually complete linearity in ${ }^{14} \mathrm{C}$ uptake over $4 \mathrm{~h}$ was observed for $D$. teriolecta when maintained under similar conditions of temperature and steady state $\mu$ (Fig. 5A). When these organisms, as well as Phaeodactylum tricornutum, and Chaetoceros simplex, were grown at different steady state temperatures down to $8{ }^{\circ} \mathrm{C}$, the onset of non-linear uptake was similarly independent of $\mu$ (data not shown).

The data in Fig. 6, on the other hand, are suggestive that temperature is important in determining when non-linear carbon uptake becomes manifest during incubation. The experiments at each temperature were conducted with cultures grown at $\mu$ values ranging from $40-60 \%$ of the maximum specific growth rate, $\hat{\mu}$, assuring that the test organisms were in the same relative physiological state (Goldman, 1980). The only exception was the experiment in which Dunaliella tertiolecta was grown close to $\hat{\mu}$ at $8^{\circ} \mathrm{C}$. However, in view of the discussion of the data in Fig. 5, the influence of high $\mu$ is not expected to be large. The incubation period for which linear carbon uptake was maintained by Thalassiosira weissflogii decreased systematically with decreasing temperature from $2.5 \mathrm{~h}$ at $25^{\circ} \mathrm{C}$ down to $\sim 0.5 \mathrm{~h}$ at $8^{\circ} \mathrm{C}$. In contrast, only slight deviations from linear uptake was observed with $D$. tertiolecta beyond incubation periods of $\sim 2.5 \mathrm{~h}$ between $25^{\circ}$ and $12{ }^{\circ} \mathrm{C}$, and there was no clear trend in this response with temperature. However, substantial non-linearity rapidly occurred at $8{ }^{\circ} \mathrm{C} .{ }^{14} \mathrm{C}$ uptake curves for Chaetoceros simplex and Phaedactylum tricornutum (data not shown) were linear over $2-3 \mathrm{~h}$ at all temperatures, including $8^{\circ} \mathrm{C}$. 
Fig. 4. Chaetoceros simplex (A, C) and Phaeodactylum tricornutum (B, D). 24-h timecourse of ${ }^{15} \mathrm{NH}_{4}^{+}$and $\mathrm{H}^{14} \mathrm{CO}_{3}^{-}$ uptake by cultures. Samples for incubation were taken from $\mathrm{NH}_{4}^{+}$limited continuous cultures maintained in steady state at $16{ }^{\circ} \mathrm{C}$ and $\mu$ of $0.65 \mathrm{~d}^{-1}$ (A, B) and $0.20 \mathrm{~d}^{-1}$ (C, D). A, B: - ${ }^{15} \mathrm{NH}_{4}^{+}$uptake (expressed as ${ }^{15} \mathrm{~N}$ atom \% excess); ${ }^{14} \mathrm{C}$ uptake (expressed as $\mathrm{dpm} \mathrm{ml}^{-1}$ ) in culture enriched with $16 \mu \mathrm{g}$ at $\mathrm{I}^{-1}$ of $\mathrm{NH}_{4}^{+} ; \Delta{ }^{14} \mathrm{C}$ uptake in unenriched culture. C, D: ${ }^{15} \mathrm{NH}_{4}^{+}$uptake; $\Delta$ residual $\mathrm{NH}_{4}^{+}$ in incubation vessel

\section{FieId Studies}

Biomass data and environmental parameters of the seawater used in the ${ }^{15} \mathrm{~N}$ and ${ }^{14} \mathrm{C}$ time-course experiments are presented in Table 1; solar irradiance data is presented in Figs. $7 \mathrm{~A}$ and $8 \mathrm{~A}$. Most notable are the facts that solar irradiance and water temperature were nearly identical for the 2 sampling dates, although the ambient $\mathrm{NH}_{4}^{+}$concentration decreased from 0.37 to

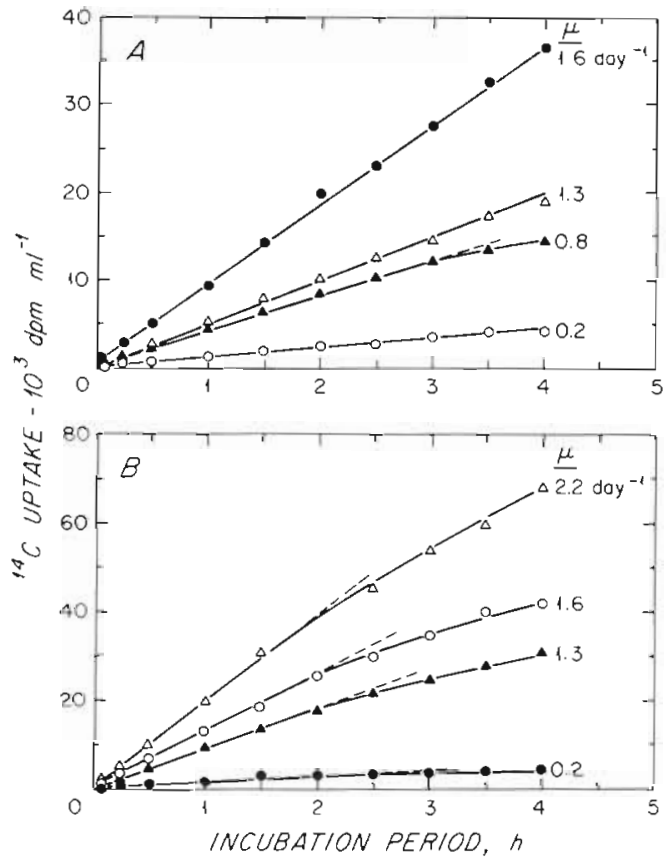

Fig. 5. Dunaliella tertiolecta and Thalassiosira weissflogii 4h time-course of $\mathrm{H}^{14} \mathrm{CO}_{3}^{-}$uptake. Samples for incubation were derived from $\mathrm{NH}_{4}^{+}$limited steady state cultures maintained at $25^{\circ} \mathrm{C}$ and at designated $\mu$. Dashed lines: points of departure from linearity, as estimated by eye. (A) D. tertiolecta; (B) $T$. weissflogii
$0.08 \mu \mathrm{g}$ at $\mathrm{l}^{-1}$ between July 24 and July 30, 1980. We have evidence to suggest that Experiment 2 was conducted during a very rapidly growing bloom of the
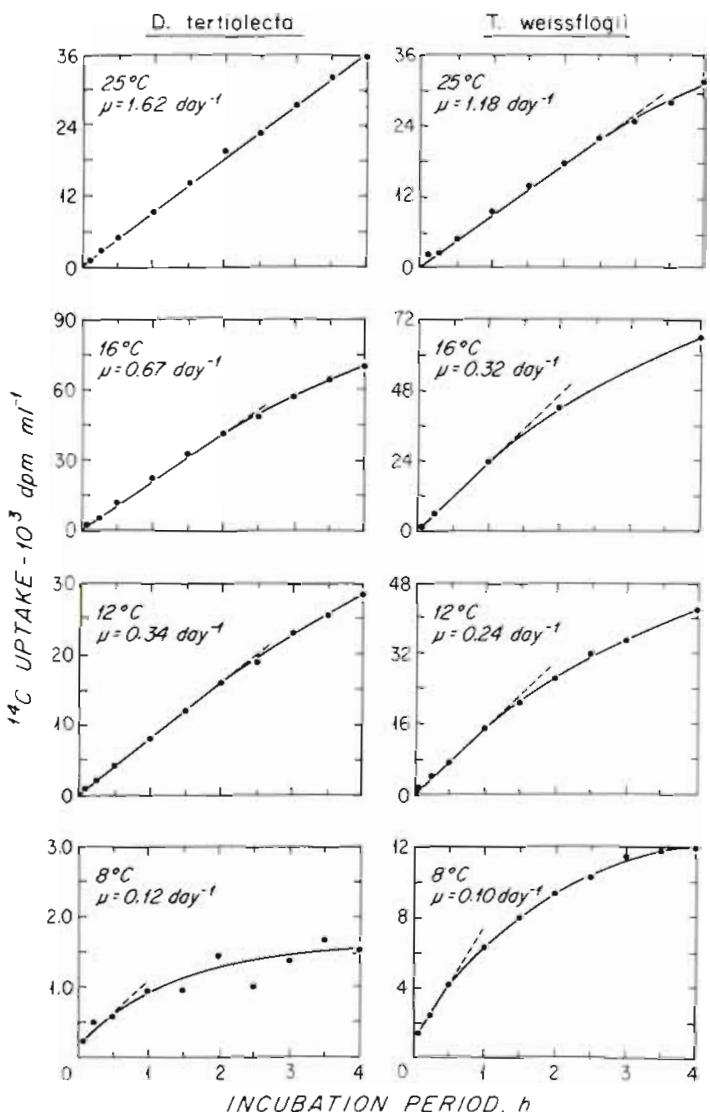

Fig. 6. Dunaliella tertiolecta and Thalassiosira weissflogii. 4h time-course of ${ }^{14} \mathrm{C}-\mathrm{HCO}_{3}^{-}$uptake. Samples for incubation were derived from $\mathrm{NH}_{4}^{+}$limited continuous cultures grown to steady state at designated temperature and $\mu$. Dashed lines: points of departure from linearity, as estimated by eye 
diatoms Asterionella japonica and Skeletonema costatum (Glibert et al., unpubl.); thus the change in ambient $\mathrm{NH}_{4}^{+}$concentrations between the 2 experimental dates is not surprising.

It is important to point out that because the incubations were performed in a series of chambers, sampled in non-sequential order, the observed fluctuations of individual points of ${ }^{15} \mathrm{~N}$ atom \% excess for a particular time series most likely were due to the combination of individual variations between sampling chambers and analytical error, and do not represent actual losses in ${ }^{15} \mathrm{~N}$ from the particulate fraction with time. For this reason the ${ }^{15} \mathrm{NH}_{4}^{+}$uptake curves shown in Figs. 7 and 8 are generalized curves that represent average trends only.

Nitrogen uptake in samples enriched with trace levels of ${ }^{15} \mathrm{NH}_{4}^{+}\left(0.06 \mu \mathrm{g}\right.$ at $\left.\mathrm{l}^{-1}\right)$ are compared in Figs. $7 \mathrm{~B}$ and $8 \mathrm{~B}$. In Experiment 1 total ${ }^{15} \mathrm{~N}$ atom $\%$ excess increased in virtually a linear fashion over the first $4 \mathrm{~h}$ and then ceased for the remainder of the incubation (Fig. 7B). In contrast, there was a significant and rapid increase in total ${ }^{15} \mathrm{~N}$ atom \% excess during the first 0.5 $\mathrm{h}$ in Experiment 2, followed by a period of reduced uptake rate and ultimately cessation of uptake after 12-15 h. Polymer incorporation, although measured with limited frequency and only in the second study, increased progressively during the entire study (Fig. 8B).

Uptake of ${ }^{15} \mathrm{NH}_{4}^{+}$was distinctly different in the 2 studies involving saturating enrichments of ${ }^{15} \mathrm{NH}_{4}^{+}(12$ $\mu \mathrm{g}$ at $\mathrm{1}^{-1}$ ) both for total nitrogen uptake and incorporation into the polymer fraction. In Experiment 1 the rate of total uptake was rapid during the first $8 \mathrm{~h}$, followed by a slowing trend over the next $13 \mathrm{~h}$, and ultimately ceasing for the remainder of the incubation (Fig. 7C). A large proportion of $\mathrm{NH}_{4}^{+}$taken up during the first $2 \mathrm{~h}$ was incorporated into polymers, but beyond that time $\mathrm{NH}_{4}^{+}$was increasingly proportioned into the soluble pool fraction as the rate of polymer incorporation slowed and finally ceased. During Experiment 2 the rates of total ${ }^{15} \mathrm{NH}_{4}^{+}$uptake and polymer incorporation

Table 1. Physical and chemical properties of Vineyard Sound (Massachusetts, USA) seawater used in $30 \mathrm{~h}$ time-course incubations

\begin{tabular}{|c|c|c|}
\hline Parameter & $\begin{array}{c}\text { July } 24 \\
1980\end{array}$ & $\begin{array}{c}\text { July } 30 \\
1980\end{array}$ \\
\hline Water temperature, ${ }^{\circ} \mathrm{C}$ & 22 & 23 \\
\hline Ambient $\mathrm{NH}_{4,}^{+} \mu \mathrm{g}$ at $\mathrm{l}^{-1}$ & 0.37 & 0.08 \\
\hline Particulate carbon, $\mu \mathrm{g} \mathrm{Cl}^{-1}$ & 624 & 829 \\
\hline Particulate nitrogen, $\mu \mathrm{g} \mathrm{N} \mathrm{l}^{-1}$ & 82 & 105 \\
\hline Chlorophyll $a_{i} \mu \mathrm{g} \mathrm{l}^{-1}$ & 1.6 & 1.3 \\
\hline Carbon: nitrogen ratio (by wt.) & 7.6 & 7.9 \\
\hline Carbon: chlorophyll ratio (by wt.) & 390 & 638 \\
\hline
\end{tabular}

(which represented most of the ${ }^{15} \mathrm{NH}_{4}^{+}$taken up) were virtually constant over the first $21 \mathrm{~h}$, but, as in the first experiment, ceased during the remainder of the incubation period (Fig. 8C).

In both trace uptake studies residual $\mathrm{NH}_{4}^{+}$decreased to undectable levels $\left(<0.03 \mu \mathrm{g}\right.$ at $\left.\mathrm{l}^{-1}\right)$ within the first $8-12 \mathrm{~h}$ of incubation. For the saturating enrichments $\mathrm{NH}_{4}^{+}$was ultimately reduced to $6 \mu \mathrm{g}$ at $\mathrm{l}^{-1}$ in Experiment 1, and to undectable levels in Experiment 2. The higher biomass and growth rate levels in Experiment 2 may explain the greater utilization of $\mathrm{NH}_{4}^{+}$.

The uptake of ${ }^{14} \mathrm{C}$ followed similar trends in the 2 field studies. Total uptake in both experiments was characterized by rapid and linear uptake of ${ }^{14} \mathrm{C}$ from morning to late afternoon $(\sim 8 \mathrm{~h})$, little uptake and possibly some losses during the night, followed by a second period of rapid uptake from the morning to mid-afternoon period of the second day (Figs. 7D and 8D). In both experiments there was little effect of supplemental trace additions of $\mathrm{NH}_{4}^{+}$on ${ }^{14} \mathrm{C}$ uptake over the entire incubation periods (Figs. 7D, 8D, 8E,

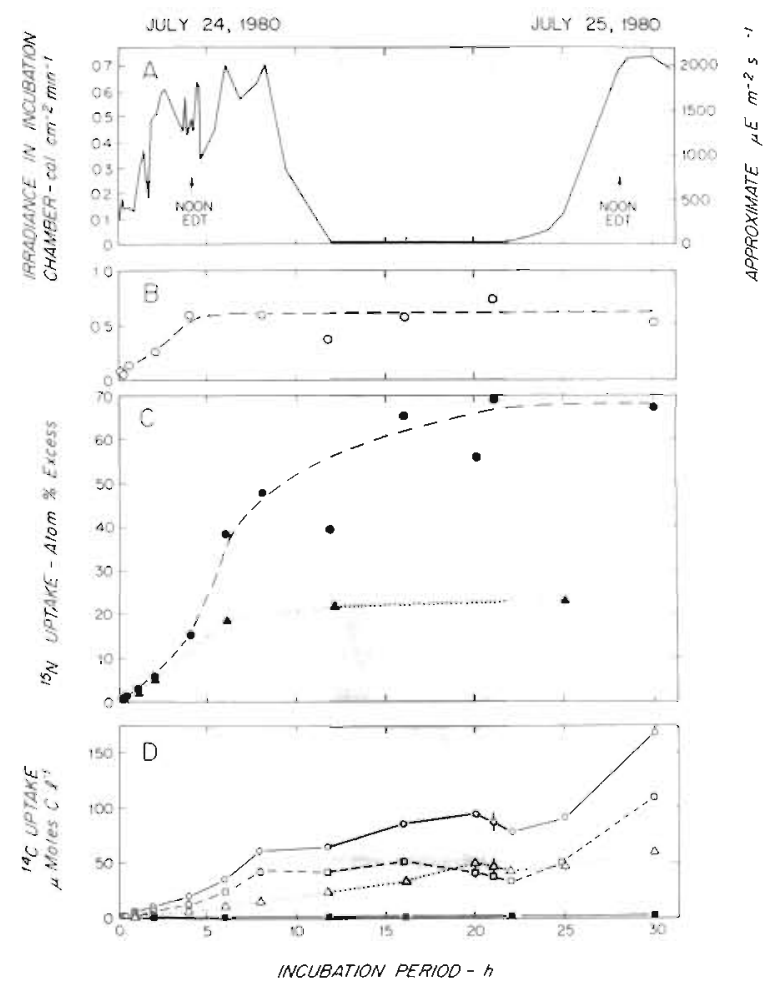

Fig. 7. 30-h field study (July 24-25, 1980) of $\mathrm{H}^{14} \mathrm{CO}_{3}^{-}$and ${ }^{15} \mathrm{NH}_{4}^{+}$uptake by natural marine populations from Vineyard Sound, Massachusetts. Ambient $\mathrm{NH}_{4}^{+}$was $0.37 \mu \mathrm{g}$ at $\mathrm{l}^{-1}$. (A) Solar irradiance. (B) ${ }^{15} \mathrm{NH}_{4}^{+}$uptake following enrichment with $0.06 \mu \mathrm{g}$ at $\mathrm{I}^{-1}{ }^{15} \mathrm{NH}_{4}^{+}$: O total $\mathrm{N}$ uptake. (C) ${ }^{15} \mathrm{NH}_{4}^{+}$uptake following enrichment with $12 \mu \mathrm{g}$ at $\mathrm{l}^{-1}{ }^{15} \mathrm{NH}_{4}^{+}$: $\bullet$ total ${ }^{15} \mathrm{NH}_{4}^{+}$ uptake; uptake into cell polymers. (D) $\mathrm{H}^{14} \mathrm{CO}_{3}^{-}$uptake. Data represent pooled experiments for no $\mathrm{NH}_{4}^{+}$enrichment and enrichment with $0.06 \mu \mathrm{g}$ at $\mathrm{l}^{-1} \mathrm{NH}_{4}^{+}: 0$ total $\mathrm{H}^{14} \mathrm{CO}_{3}^{-}$uptake; $\square$ soluble pools plus excretion products; $\triangle$ cell polymers; - total $\mathrm{H}^{14} \mathrm{CO}_{3}$ uptake in dark control 
and $8 F$ ). Uptake was enhanced on the second day for samples supplemented with saturating $\mathrm{NH}_{4}^{+}$levels relative to samples containing a trace $\mathrm{NH}_{4}^{+}$enrichment (Fig. 8D). ${ }^{14} \mathrm{C}$ uptake under saturating $\mathrm{NH}_{4}^{+}$was not investigated in Experiment 1. Uptake of ${ }^{14} \mathrm{C}$ by the dark control in Experiment 1 was negligible (Fig. 7D) and thus was not measured in Experiment 2.

A common feature of both studies was the channelling of a large fraction (70-85\%) of the total carbon

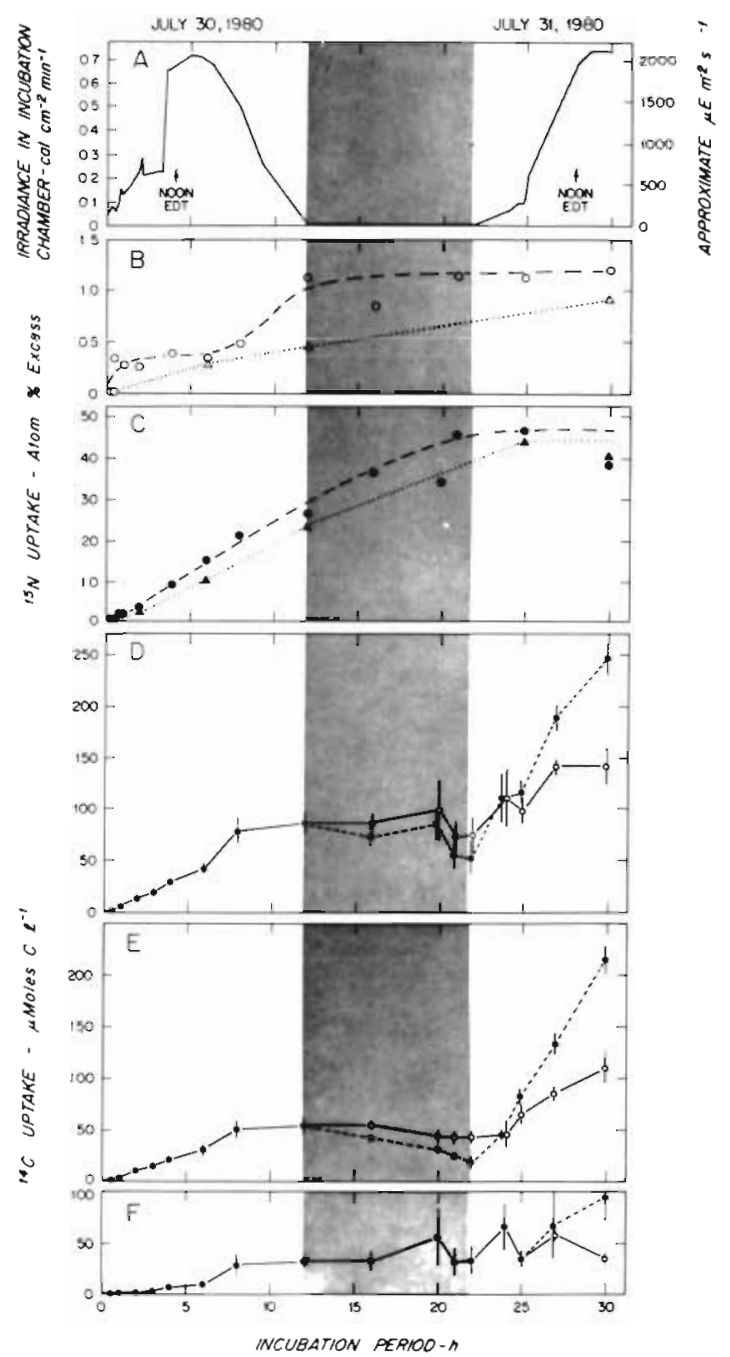

Fig. 8. 30-h field study (July 30-31, 1980) of $\mathrm{H}^{14} \mathrm{CO}_{3}^{-}$and ${ }^{15} \mathrm{NH}_{4}^{+}$uptake by natural marine populations from Vineyard Sound, Massachusetts. Ambient $\mathrm{NH}_{4}^{+}$was $0.08 \mu \mathrm{g}$ at $\mathrm{l}^{-1}$. (A) Solar irradiance. (B) ${ }^{15} \mathrm{~N}-\mathrm{NH}_{4}^{+}$uptake following enrichment with $0.06 \mu \mathrm{g}$ at $l^{-1}{ }^{15} \mathrm{NH}_{4}^{+}$: O total ${ }^{15} \mathrm{NH}_{4}^{+}$uptake; $\triangle$ uptake into cell polymers. (C) ${ }^{15} \mathrm{NH}_{4}^{+}$uptake following enrichment with $12 \mu \mathrm{g}$ at $\mathrm{I}^{-1}{ }^{15} \mathrm{NH}_{4}^{+}$; $\bullet$ total ${ }^{15} \mathrm{NH}_{4}^{+}$uptake; $\Delta$ uptake into cell polymers. (D) $\mathrm{H}^{14} \mathrm{CO}_{3}^{+}$uptake into total organic carbon. Data up to $12 \mathrm{~h}$ represent pooled experiments for unsupplemented, 0.06 , and $12 \mu \mathrm{g}$ at $\mathrm{l}^{-1}$ enrichments with $\mathrm{NH}_{4}^{+}$. Beyond $12-\mathrm{h}$; $\bullet$ $12 \mu \mathrm{g}$ at $\mathrm{l}^{-1}$ enrichment; $O$ pooled data for unsupplemented; $0.06 \mu \mathrm{g}$ at $\mathrm{I}^{-1} \mathrm{NH}_{4}^{+}$enrichment. Symbols are the same for pannels (E) and (F). (E) $\mathrm{H}^{14} \mathrm{CO}_{3}^{-}$uptake into soluble pools plus excretion products. $(\mathrm{F}) \mathrm{H}^{14} \mathrm{CO}_{3}^{-}$uptake into cell polymers taken up into soluble pools during the end of the first 8 $h$, followed by virtually no further labeling of these components (and what appeared to be a detectable loss in the saturating $\mathrm{NH}_{4}^{+}$sample during the dark period), until sunrise the next day when another rapid buildup of soluble pools occurred (Figs. 7D and 8E). A discernible effect of saturating $\mathrm{NH}_{4}^{+}$enrichment on the soluble pool fraction became manifest only after $12 \mathrm{~h}$ of incubation (Fig. 8E), and on polymer incorporation after 25 h (Fig. 8F). Essentially, linear incorporation of ${ }^{14} \mathrm{C}$ into polymers was observed for $30 \mathrm{~h}$ in Experiment 1, indicating incorporation of soluble pool material into polymers during the late afternoon and dark periods (Fig. 7D). In Experiment 2, however, polymer incorporation, like pool activity, ceased after the first $8 \mathrm{~h}$ and increased after $25 \mathrm{~h}$ only in the samples that were enriched with saturating $\mathrm{NH}_{4}^{+}$(Fig. 8F).

\section{DISCUSSION}

\section{Correlates of Non-Linearity in Bottle Incubations}

We have shown clearly that the onset of non-linear uptake of ${ }^{14} \mathrm{C}$ is not a function of steady state $\mu$ for a representative group of marine phytoplankton species cultured over a wide range of physiological states. We have also shown that temperature does not appear to affect the degree to which ${ }^{14} \mathrm{C}$ is incorporated in a linear manner for some of these species; but in the case of Thalassiosira weissflogii between $8{ }^{\circ} \mathrm{C}$ and $25^{\circ} \mathrm{C}$ and Dunaliella tertiolecta at $8^{\circ} \mathrm{C}$ temperature seems to play an important role in setting the temporal limits for linear ${ }^{14} \mathrm{C}$ uptake. Thus, if the response of $T$. weissflogii to temperature is not atypical, then a standard incubation period greater than a few hours could lead to serious underestimates of productivity in cold natural waters, and thus make meaningful comparisons of regional productivity impossible. It is hypothesized that the same effects might be observed for ${ }^{15} \mathrm{~N}$ incorporation; however, based on the data in Fig. 4 these effects would be more difficult to resolve because the linear portion of an ${ }^{15} \mathrm{~N}$ uptake curve is very short relative to a comparable ${ }^{14} \mathrm{C}$ uptake response curve.

Ultimate deviations from linearity for both $\mathrm{H}^{14} \mathrm{CO}_{3}^{-}$ and ${ }^{15} \mathrm{NH}_{4}^{+}$uptake in several of our time-course incubations appear to be correlated with $\mathrm{NH}_{4}^{+}$depletion over the course of incubation, especially in laboratory and field experiments, where $\mathrm{NH}_{4}^{+}$levels at the start of the incubations were never more than a few tenths $\mu \mathrm{g}$ at $1^{-1}$, or is perhaps due to limitation by another nutrient when complete depletion in $\mathrm{NH}_{4}^{+}$was not found. This point was demonstrated by the complete cessation in ${ }^{15} \mathrm{~N}$ atom $\%$ excess increase in both the laboratory 
experiments with saturation $\mathrm{NH}_{4}^{+}$addition after $\sim 2 \mathrm{~h}$ (Fig. 4A, B) and the outdoor studies with trace additions after $4-12 \mathrm{~h}$ (Figs. $7 \mathrm{~B}$ and $8 \mathrm{~B}$ ). The plateau in the ${ }^{15} \mathrm{~N}$ uptake time-course for laboratory and field experiments occurred within $\sim 10 \%$ of the maximum expected enrichment based on calculation of ${ }^{15} \mathrm{~N}$ added and the ambient $\mathrm{NH}_{4}^{+}$and particulate nitrogen present. This would indicate that essentially all dissolved $\mathrm{NH}_{4}^{+}$was incorporated into the particulates. It is not surprising that the maximum expected enrichment is not always achieved because, as noted above, corrections were not made for isotope dilution, which would result in an underestimation of uptake. In addition, no estimate was made of excretion of ${ }^{15} \mathrm{~N}$ as dissolved organics, which would also result in differences between the measured uptake and calculated maximum expected enrichment.

No significance can be attached to the different rates of $\mathrm{NH}_{4}^{+}$depletion in the laboratory and outdoor studies, due to the gross differences in biomass levels that were present in each type of sample. Laboratory biomass levels were typically 10-20 fold greater than in the outdoor cultures, resulting in different rates of total $\mathrm{NH}_{4}^{+}$uptake. An additional complicating factor is that in the outdoor culture the detrital contribution to the particulate nitrogen fraction cannot be estimated (McCarthy, 1980).

Short-term carbon uptake kinetics, however, were much less influenced by changes in ambient $\mathrm{NH}_{4}^{+}$ concentration than was uptake of the nutrient itself. $\mathrm{H}^{14} \mathrm{CO}_{3}^{-}$uptake, for example, remained linear and was virtually unaffected by $\mathrm{NH}_{4}^{+}$addition, even up to saturating levels (Figs. 3 and $4 \mathrm{~A}, \mathrm{~B}$ ) for the initial portion of the incubation. Hence, even under conditions of $N$ limitation (low $\mu$ relative to $\hat{\mu}$ ) internal stores of $\mathrm{N}$ generally were sufficient to allow normal photosynthesis to occur for short periods. If such a response is typical of natural populations, then shorter incubations ( $<$ several $h$ ) might provide the best representation of photosynthetic response by the undisturbed population. However, as shown by $\mathrm{Li}$ and Goldman (1981), linear uptake of ${ }^{14} \mathrm{C}$ over a few hours of incubation is not, in itself, a guarantee that the photosynthetic rate measured on a captured population in a small bottle is the same as would have occurred in the water had the sample been left undisturbed.

Over longer periods linearity in $\mathrm{H}^{14} \mathrm{CO}_{3}^{-}$uptake was maintained only in the samples containing additional $\mathrm{NH}_{4}^{+}$(Fig. 3). Even in these latter cultures $\mathrm{NH}_{4}^{+}$depletion (Fig. 4C, D) and concomitant nonlinearity (Fig. 3) occurred rapidly, e. g. $>90 \%$ depletion in $4 \mathrm{~h}$ or less. In the outdoor experiments the influence of $\mathrm{NH}_{4}^{+}$ availability on long-term photosynthesis was also evident. For example, in Experiment 2 gross differences in $\mathrm{H}^{14} \mathrm{CO}_{3}^{-}$uptake were manifested by the second day between the saturating $\mathrm{NH}_{4}^{+}$cultures and the trace and unenriched cultures which become depleted in $\mathrm{NH}_{4}^{+}$ midway through the first day of incubation (Fig. 8D).

The effect of $\mathrm{NH}_{4}^{+}$depletion on both ${ }^{15} \mathrm{NH}_{4}^{+}$and $\mathrm{H}^{14} \mathrm{CO}_{3}^{-}$uptake in these studies vividly demonstrates the potential artifact built into single end-point incubations of greater than a few h duration used to estimate rates of primary productivity and nutrient turnover. Clearly, any single datum point from a time course study is no more valid than any single end-point measurement. However, a major advantage of time course measurements of both tracer incorporation and nutrient disappearance is that deviations from linear uptake can be correlated with either real environmental influences (e. g. light variations due to clouds and diel productivity) or bottle effects such as nutrient depletion. Then data judged to be biased by bottle artifacts can be eliminated to avoid underestimates in rate measurements.

We recognize that our bottle incubations - both from laboratory and field studies - are not completely free from many of the problems cited above that are typically associated with bottle incubations (e. g. effects of bottle size or trace metal toxicity). However, a timecourse approach allows us to understand better the time-scale of physiological responses by phytoplankton and to identify the influences of environmental fluctuations and some bottle effects on the overall rate processes.

\section{Time Course of Cellular Material Incorporation}

The utility of time course incubation studies from which judgements of the physiological state of the phytoplankton community are made, either in response to natural environmental conditions or as the result of potential effects of confinement in an incubation vessel, may be enhanced significantly by measurements of the distribution of incorporated tracer substances among the subcellular components of the contained microflora.

For example, differences in the ultimate fate of nitrogen taken up by phytoplankton during the 2 field experiments were amplified by measurements of the incorporation of this element into cell polymers. For the initial $6 \mathrm{~h}$ of incubation in the presence of saturating levels of ${ }^{15} \mathrm{NH}_{4}^{+}$, both experimental samples behaved similarly, most likely reflecting rapid incorporation of nitrogen into polymers via rapid cycling of low molecular weight metabolites. However, soon thereafter there was a nearly total cessation of nitrogen-containing biopolymer synthesis by the phytoplankton population in Experiment 1. $\mathrm{NH}_{4}^{+}$was not limiting in these samples and continued uptake of the 
nutrient was dominated by its incorporation into the low molecular weight pools. The effect was clearly not evident in Experiment 2 where the initial pattern of nitrogen uptake persisted for the majority of the experiment and was totally uninfluenced by the light cycle. Continued biopolymer synthesis was also observed in samples exposed to trace levels of ${ }^{15} \mathrm{NH}_{4}^{\mathrm{N}}$. The response observed in Experiment 1 reflects an abrupt change in metabolism which departs from that observed earlier in the incubation. In this case it is not possible to discern unequivocally whether the effect was a reflection of a naturally occurring change in phytoplankton activity or was predominantly a time-dependent artifact of incubation.

Measurements of the distribution of carbon among subcellular constituents similarly will reflect with greater sensitivity the metabolic state of confined phytoplankton than will measurements of total uptake. As observed in both our laboratory (Figs. 3 and 4) and field (Figs. 7 and 8) experiments, the dynamics of total carbon uptake generally were unaffected by the ambient concentrations of $\mathrm{NH}_{4}^{+}$early in the incubation. In fact, irrespective of the $\mathrm{NH}_{4}^{+}$concentration, little quantitative difference was observed in the relative distribution of carbon between the low molecular weight and polymer fractions during the first light period of either field study. In all cases a major proportion of the newly fixed carbon was incorporated into the low molecular weight organic pools $(70-85 \%)$, the balance appearing in biopolymers. Though it is not until later in the incubation $(12-20 \mathrm{~h})$ that effects of nitrogen enrichment or limitation resulted in dramatic differences in carbon uptake dynamics, it is likely that significant compositional changes among the cellular substituents may have occurred much earlier. For example, in Experiment 2 (Fig. 8) the low molecular weight pools were significantly more labile during the dark period when high levels of $\mathrm{NH}_{4}^{+}$were present, reflecting a significant modification in the metabolism of the contained phytoplankton prior to this time. In recent photosynthesis studies (e. g. Kanazawa et al., 1970; Bassham, 1971; Hipkin and Syrett, 1977; Platt et al., 1977: Mohamed and Gnanam, 1979) increased levels of $\mathrm{NH}_{4}^{+}$have been shown to lead to modifications of cellular metabolism in response to both enhanced availability of nitrogen and enzyme regulation. Typical influences include increased synthesis of amino acids and protein relative to the production of carbohydrate precursors and polymers. Such effects can lead to significant modification in cellular composition without concomitant large changes in absolute rates of carbon uptake.

By extension of the analytical techniques beyond that employed in the present study to include measurements of the distribution of carbon among the low molecular weight pools and the major cellular polymers (i. e. protein, carbohydrate, lipid, nucleic acids) the investigator will be provided with a significantly enhanced estimate of algal physiological state. The utility of these approaches is amply illustrated by recent work from the laboratory of 1 . Morris (Morris et al., 1974; Morris and Shea, 1978; Li et al., 1980; Mague et al., 1980; Smith and Morris, $1980 \mathrm{a}, \mathrm{b}$ ). Their integration of cellular fractionation techniques with timecourse phytoplankton production measurements in the field have permitted discussion of the influences of light intensity, temperature, and nutrient limitation upon phytoplankton physiology in considerably greater detail than has been possible by classic approaches.

\section{Uncoupling Between Ammonium and Carbon Uptake}

Recently, two of us (Glibert and Goldman, 1981) demonstrated the impossibility of performing a true ${ }^{15} \mathrm{NH}_{4}^{+}$trace experiment in natural marine waters depleted of $\mathrm{NH}_{4}^{+}$. Under such conditions the 'trace addition of ${ }^{15} \mathrm{NH}_{4}^{+}\left(0.06 \mu g\right.$ at $\left.{ }^{-1}\right)$ became the major fraction of available $\mathrm{NH}_{4}^{+}$; uptake was very rapid in the first $h$ of incubation and was virtually complete within a few h. The results of our laboratory studies with Chaetoceros simplex (Fig. 4A) and Phaeodactylum tricornuturn (Fig. 4B), which were first cultured to steady state under $\mathrm{N}$ limitation and then exposed to saturating $\mathrm{NH}_{4}^{+}$, are identical in demonstrating rapid and complete uptake of $\mathrm{N}$ during first $2 \mathrm{~h}$ of incubation. Clearly, in this case estimates of $\mathrm{N}$ turnover rates based on $2 \mathrm{~h}$ incubations would have been an order of magnitude greater than those based on $24 \mathrm{~h}$. Moreover, estimates of phytoplankton growth rates based on these $N$ turnover rates would have been in gross error, judging from the tremendous disparities between the linear photosynthetic rates, and the non-linear rates of $\mathrm{NH}_{4}^{+}$uptake which approached zero shortly after the incubation began.

An even more dramatic uncoupling between photosynthetic and nutrient uptake rates was evident in our outdoor experiments. In this case the trace addition of ${ }^{15} \mathrm{NH}_{4}^{+}$represented only $14 \%$ of the total $\mathrm{NH}_{4}^{+}$available in Experiment 1, but $43 \%$ in Experiment 2. As seen in Figs. $7 \mathrm{~B}$ and $8 \mathrm{~B}$, on a scale appropriate for a 30 $h$ incubation uncoupling between carbon and ammonium uptake is not readily apparent. However, when the ${ }^{15} \mathrm{NH}_{4}^{+}$uptake data for the first $4 \mathrm{~h}$ of incubation are plotted on an expanded scale (Fig. 9), the effect of trace enrichment on initial $\mathrm{N}-\mathrm{NH}_{4}^{+}$uptake rate becomes evident: a slight surge in $\mathrm{NH}_{4}^{+}$uptake in Experiment 1 occurred in the first few min when the trace addition was a small fraction of the total $\mathrm{NH}_{4}^{+}$ pool (Fig. 9A), but a much greater surge over the first 


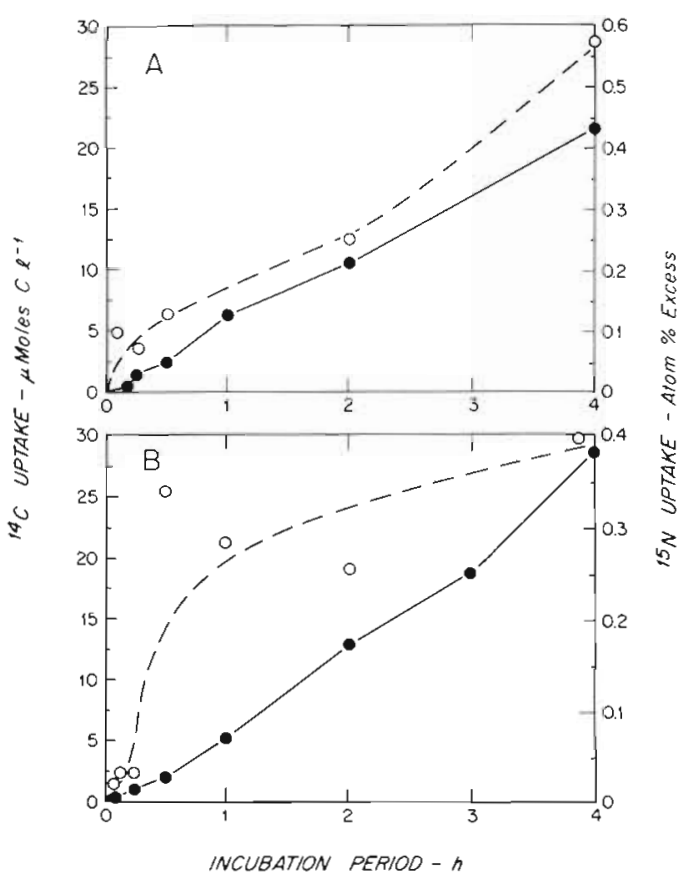

Fig. 9. First $4 \mathrm{~h}$ of $30 \mathrm{~h}$ field studies represented in Figs. 7 and 8. (A) July $24-25,1980$. (B) July $30-31,1980$. O total ${ }^{15} \mathrm{NH}_{4}^{+}$ uptake (trace addition); $-\mathrm{H}^{14} \mathrm{CO}_{3}^{-}$uptake into total organic carbon

half $h$ of incubation occurred when the ambient $\mathrm{NH}_{4}^{+}$ was almost undectable and the trace addition led to a significant transient increase in the total available $\mathrm{NH}_{4}^{+}$(Fig. 9B). Moreover, although the enhancement of $\mathrm{NH}_{4}^{+}$uptake only is evident from the expanded plot (Fig. 9B), the subsequent suppression of $\mathrm{NH}_{4}^{+}$uptake for most of the daylight $h$ of the first day can be discerned from the full scale plot in Fig. 8B.

The uncoupling between ${ }^{15} \mathrm{NH}_{4}^{+}$and $\mathrm{H}^{14} \mathrm{CO}_{3}^{-}$uptake during the first few h of Experiment 2, but not Experiment 1 , is readily apparent from a comparison of the slopes of the $\mathrm{NH}_{4}^{+}$and ${ }^{14} \mathrm{C}$ curves in Fig. 9. In both cases, $\mathrm{H}^{14} \mathrm{CO}_{3}^{-}$uptake was relatively linear over this initial portion of the incubations and did not appear to be dependent on ambient $\mathrm{NH}_{4}^{+}$. Results of these type raise serious questions about the scaling factors (both temporal and spatial) that are important in using incubation techniques to represent phytoplankton nutrient dynamics. For example, phytoplankton may depend on random and frequent exposures to even slightly elevated nutrient patches arising from the activities of closely coupled heterotrophs (McCarthy and Goldman, 1979); such responses may completely be obscured in confined samples incubated for long periods.

\section{CONCLUSIONS}

In summary, a major prerequisite for any successful bottle incubation is the recognition that there are severe incompatibilities between choosing an incubation time based solely on analytical requirements from one based on the best representation of the time scale of physiological responses by phytoplankton (Harris, 1980; McCarthy, 1980). The problem is further compounded by the difficulty in extrapolating from shortterm physiological responses to a representation of real world dynamics. In other words, even though we can define the time scale of physiological processes, we are still limited in our ability to determine production and nutrient turnover rates in oceanic surface waters where nutrient levels commonly are undetectable (McCarthy and Goldman, 1979) and rapid nutrient recycling occurs (Goldman et al., 1979). In such a system gross pertubations in nutrient flux potential may occur within the time frame of sample collection and incubation preparation so that analytical limitations may make it impossible to perform the very short incubations (possibly minutes) required to understand nutrient uptake on a physiological level and to prevent the development of major bottle artifacts (McCarthy, 1980). Time-course incubations at least allow us to identify some of these problems by the onset of nonlinearity in uptake, even if the problems cannot be eliminated completely.

Acknowledgements. The study was supported by Grants No. OCE 79-19420 (J. C. G.), OCE 79-19264 (C. D. T.) and OCE27401 (J. J. McCarthy) from the National Science Foundation. The technical assistance of Mark R. Dennett and Carol B. Riley is gratefully acknowledged.

\section{LITERATURE CITED}

Bassham, J. A. (1971). Photosynthetic carbon metabolism. Proc. natn. Acad. Sci. 68: 2877-2882

Carpenter, E. J., Lively, J. S. (1980). Review of estimates of algal growth using ${ }^{14} \mathrm{C}$ tracer techniques. In: Falkowski, P. G. (ed.) Primary productivity in the sea. Plenum Press, New York, pp. 161-178

Conway, H. L., Harrison, P. J., Davis, C. O. (1976). Marine diatoms grown in chemostats under silicate or ammonium limitation. II. Transient response of Skeletonema costatum to a single addition of a limiting nutrient. Mar. Biol. 35: $187-199$

Dugdale, R. C., Goering, J. J. (1967). Uptake of new and regenerated forms of nitrogen in primary productivity. Limnol. Oceanogr. 12: 196-206

Eppley, R. W. (1980a). Primary productivity in the sea. Nature, Lond. 286: 109-110

Eppley, R. W. (1980b). Estimating phytoplankton growth rates in the central oligotrophic oceans. In: Falkowski, P. G. (ed.) Primary productivity in the sea. Plenum Press, New York, pp. 231-242

Gieskes, W. W. C., Kraay, G. W., Baars, M. A. (1979). Current ${ }^{14} \mathrm{C}$ methods for measuring primary production: Gross underestimates in oceanic waters. Neth. J. Sea Res. 13: 58-78

Glibert, P. M., Goldman, J. C. (1981). Rapid ammonium uptake by marine phytoplankton. Mar. Biol. Lett. 2: 25-31 
Goldman, J. C. (1979). Bioengineering aspects of inorganic carbon supply to mass algal cultures. In: Proceedings Third Annual Biomass Energy Systems Conference. Rep. SERI/TP-33-285, Solar Energy Research Institute, Golden, Colorado, pp. 25-32

Goldman, J. C. (1980). Physiological processes, nutrient availability, and the concept of relative growth rate in marine phytoplankton ecology. In: Falkowski, P. G. (ed.) Primary productivity in the sea. Plenum Press, New York, pp. 179-194

Goldman, J. C., McCarthy, J. J. (1978). Steady state growth and ammonium uptake of a fast-growing marine diatom. Limnol. Oceanogr. 23: 695-703

Goldman, J. C., Peavey, D. G. (1979). Steady-state growth and chemical composition of the marine chlorophyte Dunaliella tertiolecta in nitrogen-limited continuous cultures. Appl. environ. Microbiol. 38: 894-901

Goldman, J. C., McCarthy, J. J., Peavey, D. G. (1979). Growth rate influence on the chemical composition of phytoplankton in oceanic waters. Nature, Lond. 279: 210-215

Harris, G. P. (1980). Temporal and spatial scales in phytoplankton ecology. Mechanisms, methods, models and management. Can. J. Fish. Aquat. Sci. 37: 877-900

Harris, G. P., Piccinin, B. B. (1977). Photosynthesis by natural phytoplankton populations. Arch. Hydrobiol. 80: 405-457

Hipkin, C. R., Syrett, P. J. (1977). Some effects of nitrogen starvation on nitrogen and carbohydrate metabolism in Ankistrodesmus braunii. Planta 133: 209-214

Jackson, G. A. (1980). Phytoplankton growth and zooplankton grazing in oligotrophic oceans. Nature, Lond. 284: $439-441$

Kanazawa, T., Kirk, M. R., Bassham, J. A. (1970). Regulatory effects of ammonia on carbon metabolism in photosynthesizing Chlorella pyrenoidosa. Biochim. biophys. Acta 205: 401-408

Li, W. K. W., Glover, H. E., Morris, I. (1980). Physiology of the carbon photoassimilation by Oscillatoria thiebautii in the Caribbean Sea. Limnol. Oceanogr. 25: 447-456

Li, W. K. W., Goldman, J. C. (1981). Problems in estimating growth rates of marine phytoplankton from short-term ${ }^{14} \mathrm{C}$ assays. Microb. Ecol. 7: 113-121

Mague, T. H., Friberg, E., Hughes, D. J., Morris, I. (1980). Extracellular release of carbon by marine phytoplankton: A physiological approach. Limnol. Oceanogr. 25: 262-279

Marra, J. (1978). Phytoplankton photosynthetic response to vertical movement in a mixed layer. Mar. Biol. 46: $203-208$

McCarthy, J. J. (1980). Nitrogen and phytoplankton ecology. In: Morris, I. (ed.) The physiological ecology of phytoplankton. Blackwell, Oxford, England, pp. 191-233
McCarthy, J. J., Goldman, J. C. (1979). Nitrogenous nutrition of marine phytoplankton in nutrient depleted waters. Science, N. Y. 103: 670-672

McCarthy, J. J., Kamykowski, D. (1972). Urea and other nitrogenous nutrients in La Jolla Bay during February, March, and April, 1970. Fish. Bull. U.S. 70: 1261-1274

McCarthy, J. J., Taylor, W. R., Taft, J. L. (1977). Nitrogenous nutrition of the plankton in the Chesapeake Bay. I. Nutrient availability and phytoplankton preferences. Limnol. Oceanogr. 22: 996-1011

Mohamed, A. H., Gnanam, A. (1979). A possible mechanism of ammonium ion regulation of photosynthetic carbon flow in higher plants. Plant Physiol. 64: 263-268

Morris, I., Glover, H. E., Yentsch, C. S. (1974). Products of photosynthesis by marine phytoplankton: The effect of environmental factors on the relative rates of protein synthesis. Mar. Biol. 27: 1-9

Morris, I., Shea, W. (1978). Products of photosynthesis in natural populations of marine phytoplankton from the Gulf of Maine. Mar. Biol. 47: 303-312

Platt, S. G., Plant, Z., Baasham, J. A. (1977). Ammonia regulation of carbon metabolism in photosynthesizing leaf discs. Plant Physiol. 60: 739-742

Roberts, R. B., Abelson, P. H., Cowie, D. B., Bolton, E. T., Britten, R. J. (1963). Studies of biosynthesis in Escherichia coli. Camegie Instit. Washington Publ. No. 607, Washington, D. C., $521 \mathrm{pp}$.

Schindler, D. W., Holmgren, S. K. (1971). Primary production and phytoplankton in the experimental lakes area, Northwestern Ontario and other low carbonate waters, and a liquid scintillation method for determining ${ }^{14} \mathrm{C}$ activity in photosynthesis. J. Fish. Res. Bd Can. 28: 189-201

Sheldon, R. W., Sutcliffe, Jr. W. H. (1978). Generation times of $3 \mathrm{~h}$ for Sargasso Sea microplankton determined by ATP analysis. Limnol. Oceanogr. 23: 1051-1054

Smith, A. E., Morris, I. (1980a). Synthesis of lipid during photosynthesis by phytoplankton of the Southern Ocean. Science, N. Y. 207: 197-199

Smith, A. E., Morris, I. (1980b). Pathways of carbon assimilation in phytoplankton from the Antarctic Ocean. Limnol. Oceanogr. 25: 865-872

Steemann Nielsen, E. (1952). The use of the radioactive carbon $\left(\mathrm{C}^{14}\right)$ for measuring organic production in the sea. $\mathrm{J}$. Cons. int. Expl. Mer 19: 309-328

Strickland, J. D. H., Parsons, T. R. (1972). A practical handbook of sea-water analysis. Fish. Res. Bd Can., Ottawa, pp. $87-89$

Venrick, E. L., Beers, J. R., Heinbokel, J. F. (1977). Possible consequences of containing microplankton for physiological rate measurements. J. exp. mar. Biol. Ecol. 26: 55-76 